\title{
Hand and foot pressures in the aye-aye (Daubentonia madagascariensis) reveal novel biomechanical trade-offs required for walking on gracile digits
}

\author{
Tracy L. Kivell ${ }^{1,2, *}$, Daniel Schmitt ${ }^{1}$ and Roshna E. Wunderlich ${ }^{3}$ \\ ${ }^{1}$ Department of Evolutionary Anthropology, Duke University, Box 90383, Durham, NC 27708, USA, ${ }^{2}$ Department of \\ Human Evolution, Max Planck Institute for Evolutionary Anthropology, Deutscher Platz 6, Leipzig, D-04103, Germany and \\ ${ }^{3}$ Department of Biology, James Madison University, MSC 7801, Harrisonburg, VA 22807, USA \\ *Author for correspondence (tracy_kivell@eva.mpg.de)
}

Accepted 10 January 2010

\begin{abstract}
SUMMARY
Arboreal animals with prehensile hands must balance the complex demands of bone strength, grasping and manipulation. An informative example of this problem is that of the aye-aye (Daubentonia madagascariensis), a rare lemuriform primate that is unusual in having exceptionally long, gracile fingers specialized for foraging. In addition, they are among the largest primates to engage in head-first descent on arboreal supports, a posture that should increase loads on their gracile digits. We test the hypothesis that aye-ayes will reduce pressure on their digits during locomotion by curling their fingers off the substrate. This hypothesis was tested using simultaneous videographic and pressure analysis of the hand, foot and digits for five adult aye-ayes during horizontal locomotion and during ascent and descent on a $30^{\circ}$ instrumented runway. Aye-ayes consistently curled their fingers during locomotion on all slopes. When the digits were in contact with the substrate, pressures were negligible and significantly less than those experienced by the palm or pedal digits. In addition, aye-ayes lifted their hands vertically off the substrate instead of 'toeing-off' and descended head-first at significantly slower speeds than on other slopes. Pressure on the hand increased during head-first descent relative to horizontal locomotion but not as much as the pressure increased on the foot during ascent. This distribution of pressure suggests that aye-ayes shift their weight posteriorly during head-first descent to reduce loads on their gracile fingers. This research demonstrates several novel biomechanical trade-offs to deal with complex functional demands on the mammalian skeleton.
\end{abstract}

Supplementary material available online at http://jeb.biologists.org/cgi/content/full/213/9/1549/DC1

Key words: hand posture, fingers, foot, toes, slope.

\section{INTRODUCTION}

Grasping prehensile hands are a critical adaptive innovation for arboreal primates and many arboreal marsupials because they are advantageous for both foraging and food manipulation as well as for maintaining a secure grip on complex and discontinuous supports (Cartmill, 1972; Cartmill, 1992; Lemelin, 1999; Lemelin and Grafton, 1998; Hamrick, 2001). There are, however, substantial biomechanical disadvantages to having a prehensile grasp. The disadvantages include higher intrinsic and extrinsic muscle mass concentrated relatively distally along the forelimb that increases the second moment of area and thereby increasing the cost of swinging the limb (Preuschoft and Günther, 1994; Raichlen, 2004; Raichlen, 2005). Another significant disadvantage is the need for long, gracile metacarpals and phalanges with flexible joints to maintain finger mobility and enhance grip (Cartmill, 1974; Lemelin, 1999; Lemelin and Schmitt, 2007). The long, gracile digits of many primates and marsupials are more susceptible to fracture failure than shorter more robust bones would be (Swartz and Biewener, 1992). Thus, these animals must balance the conflicting needs of strength and manipulative mobility, and they do so in several interesting ways.

The prehensile hands of highly terrestrial primates such as baboons and other large-bodied papionins (Napier, 1963; Napier and Napier, 1967; Strasser, 1992; Strasser, 1994) as well as terrestrial marsupials such as Monodelphis (Lemelin, 1999; Lemelin and Schmitt, 2007) that do not need long, curved phalanges for arboreality, possess relatively short, robust phalanges compared with their more arboreal counterparts. By contrast, other primates that need to maintain long, curved phalanges for suspensory or climbing behaviors adopt a behavioral solution by curling their long fingers into a knuckle-walking or fist-walking posture, as in great apes (Tuttle, 1967; Tuttle, 1969; Susman, 1974; Inouye, 1994) or bowup their fingers, as in small-bodied prosimians and some New World monkeys (Lemelin, 1996), to reduce bending loads on the digits during quadrupedal locomotion. Other arboreal animals such as the spider monkey adopt extreme positions of ulnar deviation (in which the line formed by fifth ray and the ulna is made more acute) that place the long digits perpendicular to sagittal bending loads (Preuschoft et al., 1993; Lemelin and Schmitt, 1998).

These solutions represent important ways in which primates reduce bending load on the relatively long, gracile digits of a grasping hand during horizontal locomotion. However, changes in posture or substrate inclination could increase bending loads and mitigate the effectiveness of these solutions. For example, headfirst descent down oblique or vertical substrates would theoretically increase the amount of weight support on the forelimb relative to the hindlimb (Dutto et al., 2004; Lammers et al., 2006; Lammers, 2007; Lee et al., 2008). How animals cope with the potential biomechanical challenges posed by head-first descent is poorly understood but highly relevant to understanding both limb design and locomotor behavioral choices. 
To best understand the manner in which animals deal with these potential challenges it is worth examining the most extreme cases. Several mammalian groups have convergently evolved highly elongated digits for foraging and thus must reconcile the biomechanical challenges associated with locomotion. The marsupial Dactylopsila palpator (the long-fingered triok) and the extinct, early Tertiary insectivore, Heterohyus, both have remarkably elongated third and/or fourth digits that are subject to potentially high locomotor loads (Cartmill, 1974; Schaal and Ziegler, 1992; Flannery, 1995). However, Daubentonia madagascariensis (the ayeaye), a rare lemuriform primate, is perhaps the most remarkable example in that the digits are not only extremely elongated, but are also gracile. Furthermore, the aye-aye frequently engages in headfirst descent that will presumably greatly increase bending loads on these slender fingers. Thus the focus of this paper is on developing and testing hypotheses about behavioral solutions to these biomechanical challenges in the aye-aye.

Aye-ayes have the largest hands relative to body size within the primates; their hands make up almost half the total length of the forelimb (Ashton et al., 1975; Jouffroy and Lessertisseur, 1979; Oxnard, 1981; Jouffroy et al., 1991; Lemelin and Jungers, 1997; Soligo, 2005; Sterling and McCreless, 2006). The aye-aye hand is ectaxonic (i.e. the fourth ray is the longest) like those of most strepsirrhines (Lessertisseur and Jouffroy, 1973; Strasser, 1994; Lemelin and Schmitt, 1998), but the fourth ray is extremely long relative to those of other primates (Fig. 1). The gracile, probe-like third digit is also remarkably long, due largely to an elongated metacarpal with a highly mobile ball-and-socket metacarpophalangeal joint (Owen, 1866; Jouffroy, 1975; Soligo, 2005) that is specialized for extracting grubs during foraging (Milliken et al., 1991; Erickson, 1994). In addition, the aye-aye is the largest arboreal primate (at $2.5 \mathrm{~kg}$ ) regularly to engage in headfirst descent (Ancrenaz et al., 1994; Curtis and Feistner, 1994). Thus, the aye-aye represents an ideal natural subject to explore behavioral and kinematic solutions to potentially high loads on long, gracile hands.

Locomotion on incline and decline slopes has the potential to alter load distribution on the limbs. The line of gravity passing through the animals' center of mass intersects the substrate closer to the hindlimbs on the incline slope and closer to the forelimbs on a decline slope (Lammers, 2007). In a kinetic study of incline and decline locomotion in the Monodelphis domestica (gray short-tailed opossum), Lammers et al. (Lammers et al., 2006) found that the relative weight support shifted from $67 \%$ on the forelimb during level locomotion to equal distribution between forelimbs (51\%) and hindlimbs (49\%) during ascending locomotion. Conversely, the forelimbs supported the majority of body weight (82\%) during descending locomotion (Lammers et al., 2006). Similarly, Lee et al. (Lee et al., 2008) found that the ground reaction resultant greatly increased on pygmy goat forelimbs during descent and, conversely, was significantly reduced during ascent. Relative to horizontal locomotion, horses traveling uphill also experienced a $5 \%$ posterior shift in the distribution of force between the forelimbs and hindlimbs (Dutto et al., 2004). Taken together, these studies of ground reaction forces suggest that the relative pressure experienced by the forelimbs should similarly increase during head-first descent in aye-ayes.

Little is known about how aye-ayes manage this theoretical biomechanical challenge of having, (1) long, gracile digits that are not well designed for resisting increased stress and, (2) the potential for increased stress on digits generated as a result head-first descent. Behavioral studies suggest that aye-ayes curl their fingers off the substrate during horizontal and descending locomotion, placing the entire forelimb load on the palm (Oxnard et al., 1990). However, in a study of arboreal locomotion, Krakauer et al. (Krakauer et al., 2002) showed that aye-ayes do not always curl all fingers off the substrate. Instead, they found that the animals in their study used a variety of different hand postures, including postures in which the digits make direct contact with the substrate. In a full-grip hand

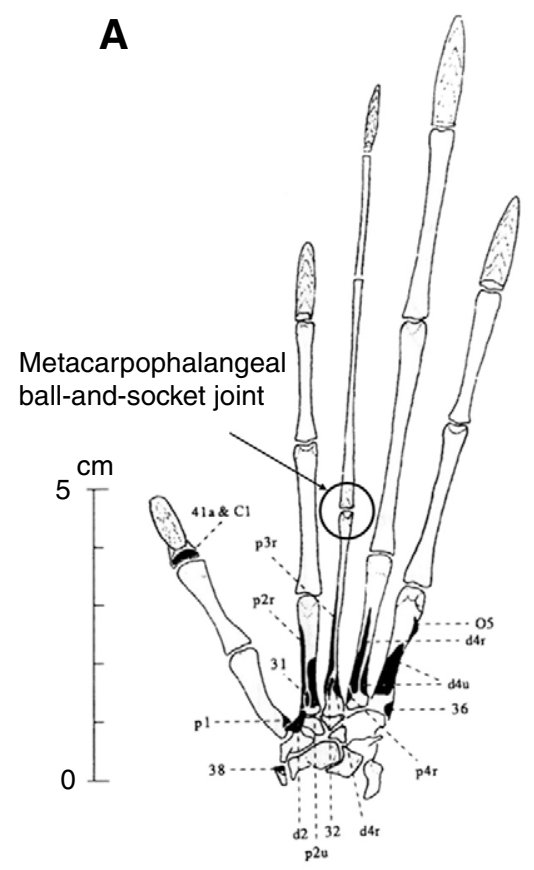

Aye-aye
B

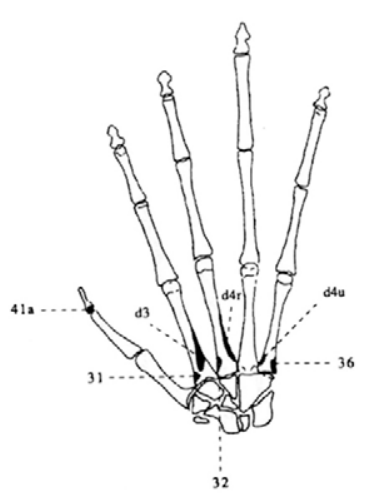

Ring-tailed lemur

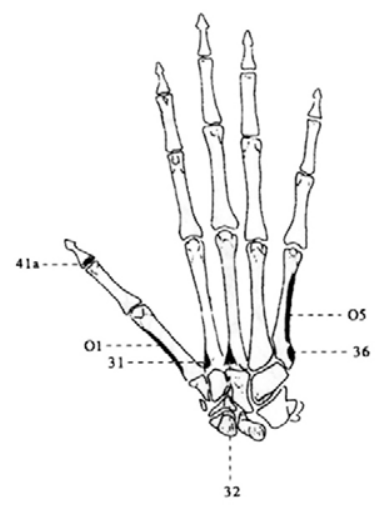

Fig. 1. The specialized hand morphology of the aye-aye. The hand skeleton of the aye-aye (A) in comparison with that of two other primates $(B, C)$, demonstrating the extreme length of the fourth digit and long, fragile third digit with a ball-andsocket metacarpophalangeal joint (adapted from Soligo, 2005). 
posture, digits II-V are curled around the support with the thumb on the opposing side of the support. In a bowed-finger grip the second digit is curled on top of the support and digits III-V grip the support or are slightly bowed as well (Krakauer et al., 2002). Although we do not know how hand postures change on broader or flatter substrates, the frequent use of the third and fourth highly specialized digits during quadrupedal arboreal locomotion (Krakauer et al., 2002) suggests that aye-ayes are potentially reducing the load experienced by the digits in some other way rather than simply avoiding bending stress by curling their digits off the substrate. Krakauer et al. (Krakauer et al., 2002) suggested that aye-ayes may be shifting their weight posteriorly over their hindlimbs during headfirst decent relative to horizontal locomotion to reduce forelimb load. This hypothesis has yet to be empirically tested.

In order to examine relative pressure distribution on the forelimb and hindlimb while simultaneously assessing the relative pressure distribution on the manual digits and palm, it is necessary to collect dynamic pressures of the hands and feet. Little is known about the pressures experienced by the hands and feet during locomotion in nonhuman primates, especially on sloped surfaces. Most research has focused on plantar pressures in apes (Elftman and Manter, 1935; Wunderlich, 1999; Vereecke et al., 2003; Vereecke et al., 2005), especially during bipedal locomotion (Elftman and Manter, 1935; Wunderlich, 2003; D’Août et al., 2004; Vereecke et al., 2005), and cercopithecoid monkeys (Wunderlich, 1999; Patel and Wunderlich, 2010). Studies specifically focused on pressures placed on the hands of nonhuman primates during locomotion are limited to chimpanzees (Wunderlich and Jungers, 2009), gibbons, patas monkeys and crab-eating macaques (Richmond, 1998). To date, there have been no pressure studies on aye-ayes or any other strepsirrhine primate.

Aye-ayes need long digits for grasping branches and foraging, so short digits or knuckle- or fist-walking postures, adaptations used by other primates to reduce bending load on the manual digits, are not an option. Aye-ayes also need slender digits for foraging, so they cannot simply increase bone cross-sectional area. Therefore, aye-ayes require a new solution. As described above, finger-curling off of the substrate may represent that solution but shifting weight away from the manual digits, either to the palm or to the hindlimbs, is a solution that facilitates gracility in the hand and potentially the whole forelimb. This report takes a laboratory-based approach to testing for these potential adaptive strategies.

Documenting the specific pressures experienced by the manual digits and palm, and their relationship to pressures experienced by the foot, during quadrupedal locomotion will help to clarify the range of options available to the aye-aye and potentially other longfingered mammals for reconciling conflicts between the maintenance of specialized manual morphology and the use of locomotor patterns that have the potential to increase load on these elements. Based on previous reports and on the expectations that aye-ayes, like other long-fingered primates, will attempt to reduce bending loads on their digits, we can develop specific hypotheses. First, aye-ayes will curl their digits up off the substrate on all slopes, but this curling may be most pronounced during head-first descent when forelimb load would be highest. Second, even when they do not curl the digits off of the substrate, we predict that the load on the manual digits will be low relative to that of the palm and the pedal digits. This pattern is also expected to be most extreme during head-first descent. Finally, following Krakauer et al. (Krakauer et al., 2002), we hypothesize that aye-ayes will shift weight onto the hindlimbs in an attempt to reduce bending load on the manual digits. Thus on all slopes we might predict that forelimb pressures will be lower than those of the hindlimb, as is the case with most primates (e.g. Kimura, 1985; Demes et al., 1994), and that pressures of the manual digits will be less than those of the palm. However, substrate incline is a complicating factor and unless aye-ayes find a way to compensate for this, such as changes in body axis as suggested by Krakauer et al. (Krakauer et al., 2002), forelimb pressures will increase on declined slopes and decrease on inclined slopes relative to horizontal locomotion.

\section{MATERIALS AND METHODS}

We investigated hand and foot pressure in aye-ayes (Daubentonia madagascariensis Gmelin 1788) during horizontal, ascending and descending quadrupedal locomotion at the Duke Lemur Center, NC, USA. All research was approved by Duke University Institutional Animal Care and Use Committee. A $243 \mathrm{~cm} \times 61 \mathrm{~cm}$ (length $\times$ width) adjustable wooden ramp was constructed and equipped with a EMED-ST (Novel Inc., St Paul, MN, USA) pressure platform embedded flush within the substrate (Fig. 2A) following the methods

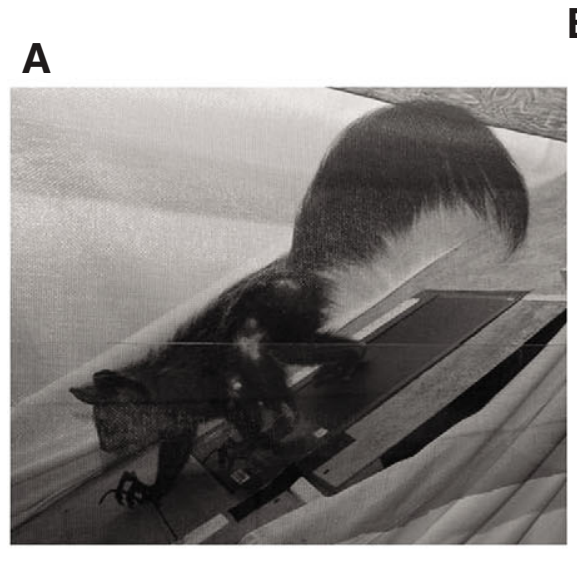

B

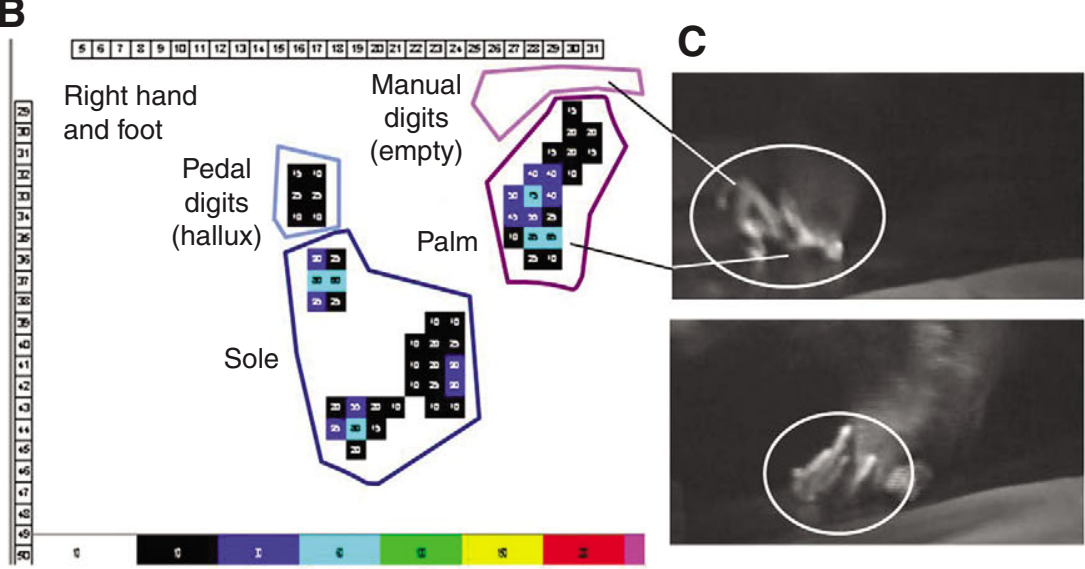

Fig. 2. Example of aye-aye analytical set up. (A) Aye-aye descending a $30^{\circ}$ wooden ramp with pressure platform embedded flush within the substrate.

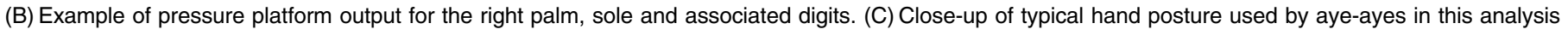

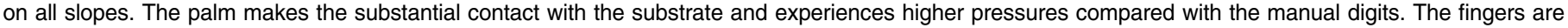
curled up off the substrate throughout the step, such that often only pressure on the pollex is recorded or no pressure at all for the manual digits. 
of Vereecke et al. (Vereecke et al., 2003; Vereecke et al., 2005), D'Août et al. (D'Août et al., 2004) and Wunderlich and Jungers (Wunderlich and Jungers, 2009). The ramp could be adjusted to be horizontal and inclined at a $30 \mathrm{deg}$. angle. The ramp was coated in a mixture of sand and varnish to create a nonslip surface. Five adult aye-ayes were motivated by food to walk freely up and down the ramp or on the horizontal substrate. Not all individuals were cooperative on all days or substrates, and thus data were not collected on all substrates for all individuals. Since the pressure platform is an inflexible structure, it can only simulate locomotion on the ground or large boughs or tree trunks and not locomotion on smaller substrates on which grasping is possible. In the wild, aye-ayes prefer oblique substrates over vertical or horizontal, and they travel along large diameter $(>10 \mathrm{~cm})$ substrates roughly $25 \%$ of their locomotor time (Ancrenaz et al., 1994). Although aye-ayes do sometimes descend substrates that are more vertical than a $30 \mathrm{deg}$. angle, this study did not want to confound walking on inclines with 'climbing' [e.g. 45 deg. or greater (Prost and Susman, 1969; Vilensky, 1994; Gebo, 1996; Hunt et al., 1996)], so we avoided larger angles that would have posed a challenge for the animals to ascend. The pressure platform collects pressure at $50 \mathrm{~Hz}$ with four sensors per $\mathrm{cm}^{2}$ over a $26 \times 40 \mathrm{~cm}$ sensor area. It is of note that the pressure platform only measures pressure normal to the platform, so braking and propulsive forces are not accounted for in this analysis (also see below). Maximum pressure, pressure-time integrals and contact time for the palm, sole, manual and pedal digits were quantified using the Novel-Win software package (Novel Inc., St Paul, MN, USA) as animals walked over the pressure platform. A total of 146 walking steps (Table 1), were used for the pressure distribution analysis.

Aye-ayes are nocturnal and thus, to avoid undue stress and to simulate the most natural conditions, all experiments were run in the dark under red-light. Two Sony HDR-S11 Handycam cameras videotaped the animals, at $60 \mathrm{~Hz}$ using the night-shot function, as they walked over the pressure platform. One camera provided a lateral view of the entire animal over a range of at least three strides, so as to assess speed. The other camera was positioned obliquely for a close-up view of the hand in order to assess hand posture and to verify the digital identification of the pressure tracings. Video from each camera was fed into a Panasonic WJ-45P special effects generator in order to view both images simultaneously on a splitscreen video.

Peak pressure $\left(\mathrm{Ncm}^{-2}\right)$ for the palm, manual digits, sole and pedal digits were computed frame-by-frame and over the entire step (Fig. 2B). The palm and sole were defined as any contact area between the heel/proximal palm and distal end of the metacarpal/tarsals. Digit contact area was defined as any region making contact with the substrate distal to the metacarpal/tarsal heads. Contact time (time between initial hand/foot contact and lift-off) was also analyzed for each anatomical area. Pressure-time integrals $\left[\left(\mathrm{N} \mathrm{cm}^{-2}\right) \times \mathrm{sec}\right]$ were calculated for each region, as this quantity represents the total pressure experienced by a region by incorporating both pressure

Table 1. Number of steps on each slope for each individual

\begin{tabular}{lccccc}
\hline & \multirow{2}{*}{$\begin{array}{c}\text { Body mass } \\
\text { Individual }\end{array}$} & & \multicolumn{3}{c}{ Steps on angled substrate } \\
\cline { 5 - 6 } & $(\mathrm{g})$ & Sex & Descent & Horizontal & Ascent \\
\hline A & 2830 & - & 32 & 19 & 28 \\
B & 2840 & - & 3 & 9 & 21 \\
C & 2300 & - & 4 & - & 5 \\
D & 2340 & - & - & 4 & - \\
E & 2120 & - & - & 22 & - \\
Total & & & 39 & 54 & 54 \\
\hline
\end{tabular}

and the time over which the region is loaded. In other words, this value is a measure of the area under the pressure-time curve. Total pressure over time was also summed for the hand (palm and manual digits) and foot (sole and pedal digits) to analyze the relative distribution of pressure between the forelimbs and hindlimbs.

Because the pressure platform only measures pressure normal to the platform and this normal vector is only a component of the total weight vector (pressure $\times \cos 30 \mathrm{deg}$. if static) on a slope but equivalent to the total weight vector on a horizontal surface (pressure $\times \cos 90 \mathrm{deg}$. if static), we only directly compared peak pressure on equally sloped surfaces (i.e. $30 \mathrm{deg}$. ascent and $30 \mathrm{deg}$. descent). Comparisons of the peak pressure and pressure-time integral were also expressed as a dimensionless ratio. The peak pressure of the forelimb (i.e. palm) was divided by the peak pressure of the hindlimb (i.e. sole) for comparisons with literature on the relative distribution of peak vertical forces across the limbs in other primates (Kimura et al., 1979; Reynolds, 1985; Demes et al., 1994; Schmitt and Lemelin, 2002). The pressure-time integral was expressed as a percentage ratio of the regional pressure-time integral over the total pressure-time integral for all regions (e.g. pressure experienced by the palm/total pressure experienced by all areas of the fore- and hind limbs $\times 100$ ) to provide comparable tests across both horizontal and sloped substrates. These ratios were arcsine-transformed for all statistical analyses to improve normality and allow very low and very high values more theoretical freedom to vary (Quinn and Keough, 2002). Throughout the paper, the percent ratio of the pressure-time integral (PTI) will be referred to as the 'PTI ratio'.

Means and standard deviations were calculated for each variable described above and differences were assessed between individuals and slopes. Speed $\left(\mathrm{m} \mathrm{s}^{-1}\right)$ of each trial was calculated from digital video sequences by dividing the length of a known distance by the time taken by the animal to cross that distance. Variation in mean speed for all pairwise comparisons of individuals and slopes was assessed using an analysis of variance (ANOVA). Results showed that there was significant variation in speed across slopes. Therefore, Spearman's rho correlation coefficient $\left(r_{\mathrm{s}}\right)$ was used to test for significant relationships between speed and each variable across all slopes combined. For variables that were significantly $(P<0.05)$ correlated with speed, variation among individuals and slopes was assessed using an analysis of covariance (ANCOVA) with speed as the covariate. For variables that did not yield a significant correlation with speed, differences among individuals and slopes were assessed using ANOVA. A post-hoc Tukey honestly significant

Table 2. Frequency (\%) of hand postures used by each individual on each slope

\begin{tabular}{|c|c|c|c|c|c|c|}
\hline \multirow[b]{2}{*}{$\begin{array}{l}\text { Angled } \\
\text { substrate }\end{array}$} & \multirow[b]{2}{*}{ Individual } & \multirow[b]{2}{*}{$N$} & \multirow[b]{2}{*}{$\begin{array}{c}\text { No digits } \\
(\%)\end{array}$} & \multirow[b]{2}{*}{$\begin{array}{l}\text { Digits } \\
(\%)\end{array}$} & \multicolumn{2}{|c|}{$\begin{array}{c}\text { When manual } \\
\text { digits used }\end{array}$} \\
\hline & & & & & $\begin{array}{l}\text { Pollex } \\
\text { only (\%) }\end{array}$ & $\begin{array}{c}\text { Medial } \\
\text { digits (\%) }\end{array}$ \\
\hline \multirow[t]{3}{*}{ Descent } & A & 31 & 0 & 100 & 97 & 3 \\
\hline & B & 3 & 100 & - & - & - \\
\hline & C & 4 & 100 & - & - & - \\
\hline \multirow[t]{4}{*}{ Horizontal } & A & 18 & 0 & 100 & 39 & 61 \\
\hline & B & 9 & 56 & 44 & 22 & 22 \\
\hline & D & 4 & 50 & 50 & 100 & - \\
\hline & $E$ & 17 & 59 & 41 & 100 & - \\
\hline \multirow[t]{3}{*}{ Ascent } & A & 28 & 21 & 79 & 77 & 23 \\
\hline & $B$ & 22 & 18 & 82 & 61 & 39 \\
\hline & C & 4 & 75 & 25 & 100 & - \\
\hline
\end{tabular}



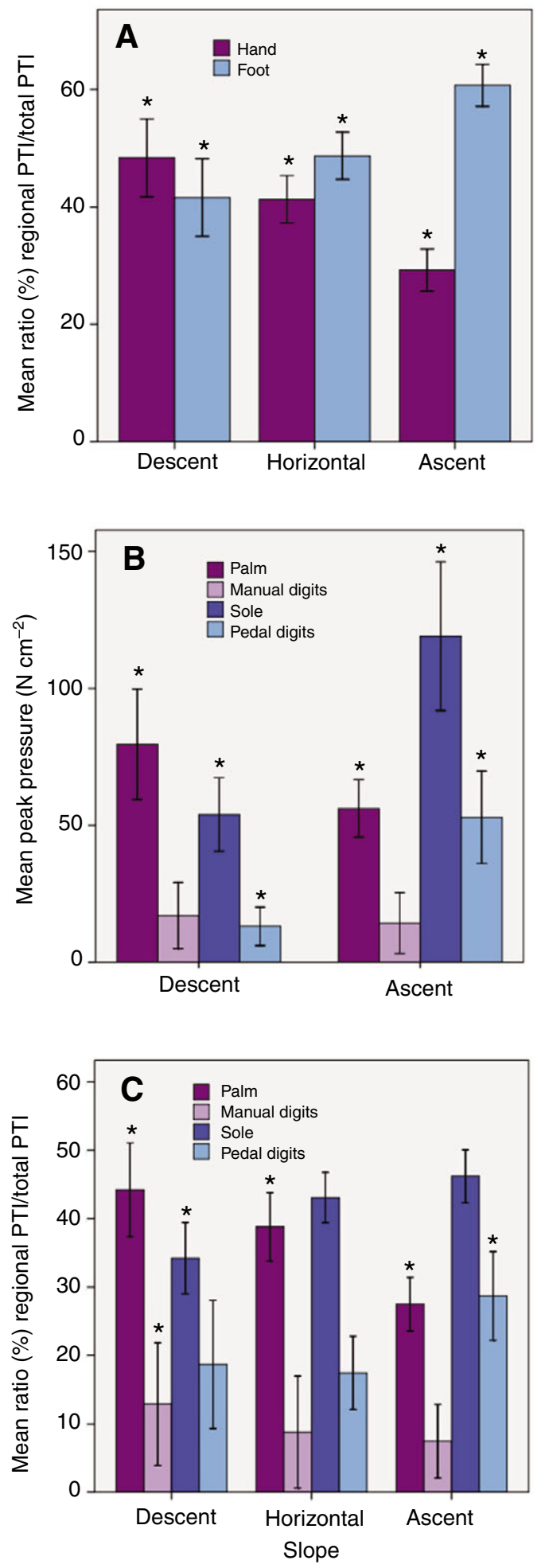

Fig. 3. Comparison of pressure on each anatomical region across slopes (individuals pooled). (A) Mean ratio (percentage) of the regional pressure-time integral (PTI)/total PTI for both limbs $\times 100$ across all slopes for the hand (palm + manual digits) and foot (sole + pedal digits). (B) Mean peak pressure $\left(\mathrm{N} \mathrm{cm}^{-2}\right)$ of the palm, manual digits, sole and pedal digits between the $30 \mathrm{deg}$. sloped substrates. Significant $\left({ }^{\star} P<0.05\right)$ differences in peak pressure were found between the slopes for all anatomical regions except the manual digits. (C) Mean PTI ratio across all slopes for the palm, manual digits, sole and pedal digits. For significant $\left({ }^{\star} P<0.05\right)$ differences in the PTI ratio see Table 5 and the text for further explanation. during ascending locomotion (supplementary material Tables S2 and S3).

The distribution of pressure between hands and feet on the 30 deg. slopes showed a clear pattern of load shifting. Referring to peak pressures on the entire hand and foot is the effective equivalent of referring to peak pressures on just the palm and sole, respectively, because the latter regions consistently experienced the highest pressures that always exceeded those of the digits. A ratio of the peak pressure of the hand over the peak pressure of the foot revealed significantly $(F$-ratio $=180.74$, $P<0.01$ ) higher peak pressure on the hand during descent (mean peak pressure ratio $=1.95$ ) compared with ascent $(0.49)$. Individual variation in the peak pressure ratio was found only during descent with Individual $\mathrm{C}$ having a significantly $(F=17.03, P<0.01)$ higher ratio (2.76) than Individuals A (1.39) and B (1.70). The same hand/foot peak pressure ratio was calculated for horizontal locomotion to compare with the values in the literature on the relative limb distribution of peak vertical force in other primates and to test for significant individual variation. On the horizontal substrate, aye-ayes had a peak pressure ratio of 0.88 and there were no significant differences among individuals.

Analysis of variation in the PTI ratios for the hand $(F$-ratio $=15.41$, $P<0.01)$ and foot $(F$-ratio=15.41, $P<0.01)$ revealed significant differences in the relative pressure experienced between the limbs on all slopes (individuals pooled). During horizontal locomotion, the hand experienced on average $44 \%$ of the total PTI and the foot $56 \%$ (Fig. 3A). During head-first descent, the hand experienced significantly higher pressures $(54 \%)$ while the foot experienced significantly lower pressures (46\%) compared with the other slopes. The inverse pattern was true during ascending locomotion, with the hand experiencing significantly lower pressures $(25 \%)$ and the foot significantly higher pressures (75\%). All significant individual variation was explained by Individual A with a lower percentage of the PTI ratio on the hand $(F$-ratio $=38.61, P<0.01)$ and higher percentage on the foot $(F$-ratio $=38.61, P<0.01)$ during decent compared with Individual B (supplementary material Table S3).

Within the hand, analyses of peak pressure across $30 \mathrm{deg}$. slopes revealed that peak pressure on the palm was significantly $(F$ ratio=48.60, $P<0.01$ ) higher during descending locomotion than during ascent (Fig. 3C). However, there was no significant $(F$ ratio $=3.10, P=0.08$ ) difference in the peak pressure experienced by the manual digits between descending and ascending locomotion, possibly because of the rare use and light pressure applied (Table 2; Fig. 3B).

As can be seen in Table 5, assessment of variation in the PTI ratios of the palm revealed significant differences between all slope pair-wise comparisons. The palm experienced significantly $(F$-ratio=83.30, $P<0.01)$ higher percentage of the total PTI during head-first descent (mean 53\%) compared with horizontal (39\%) and ascending (22\%) locomotion, with the converse pattern holding true for ascending locomotion (Table 5; Fig. 3C). The manual digits experienced significantly $(F$-ratio $=9.01, P<0.01)$ higher pressure during descent $(10 \%)$ compared with all other slopes, but there was no significant difference between horizontal (4\%) and ascending (3\%) locomotion (Table 5; Fig. 3C). Individual A was the only subject to use their manual digits during descent and thus experienced significantly higher PTI $(F$ ratio $=17.61, P<0.01)$ and peak pressure $(F$-ratio $=14.89, P<0.01)$ than all the other individuals on the same slope (supplementary material Tables S2 and S3).

Analysis of variation within the foot revealed a similar pattern to that of the hand. Peak pressure experienced by the sole $(F-$ 
Table 5. The percent ratio of the pressure-time integral and significant differences across slopes for the hand (palm + manual digits), palm and manual digits as well as foot (sole + pedal digits), sole and pedal digits

\begin{tabular}{|c|c|c|c|}
\hline Anatomical region/slope & Descent & Horizontal & Ascent \\
\hline \multicolumn{4}{|l|}{ Hand } \\
\hline Descent & 53.99 & * & * \\
\hline Horizontal & * & 43.63 & * \\
\hline Ascent & * & * & 25.18 \\
\hline \multicolumn{4}{|l|}{ Palm } \\
\hline Descent & 52.99 & * & * \\
\hline Horizontal & * & 39.24 & * \\
\hline Ascent & * & * & 22.34 \\
\hline \multicolumn{4}{|l|}{ Manual digits } \\
\hline Descent & 9.63 & * & * \\
\hline Horizontal & * & 4.46 & \\
\hline Ascent & * & & 2.83 \\
\hline \multicolumn{4}{|l|}{ Foot } \\
\hline Descent & 46.01 & * & * \\
\hline Horizontal & * & 56.37 & * \\
\hline Ascent & * & * & 74.82 \\
\hline \multicolumn{4}{|l|}{ Sole } \\
\hline Descent & 32.21 & * & * \\
\hline Horizontal & * & 48.13 & \\
\hline Ascent & * & & 51.62 \\
\hline \multicolumn{4}{|l|}{ Pedal digits } \\
\hline Descent & 13.38 & & * \\
\hline Horizontal & & 10.08 & * \\
\hline Ascent & * & * & 23.86 \\
\hline \multicolumn{4}{|c|}{$\begin{array}{l}\text { PTI, pressure-time integral; PTI ratio, PTI of anatomical region/total } \\
\text { PTI } \times 100 \text {. }\end{array}$} \\
\hline
\end{tabular}

ratio $=15.56, P<0.01)$ and pedal digits $(F$-ratio $=4.70, P=0.03)$ were significantly lower during head-first descent than during ascending locomotion (Fig. 3B). The PTI ratio of the sole was significantly ( $F$-ratio $=43.91, P<0.01)$ lower during head-first descent compared with locomotion on all other substrates (Fig. 3C; Table 5). However, there was no significant difference in sole PTI ratio between horizontal and ascending locomotion. Analysis of variation in the PTI ratio of the pedal digits revealed that pressures were significantly ( $F$-ratio $=33.49, P<0.01)$ higher during ascending locomotion than on all other slopes, but there was no significant difference between horizontal and descending locomotion (Fig. 3C, Table 5).

Significant individual variation in peak pressure was found only during ascent, with Individual $\mathrm{C}$ having lower $(F$-ratio $=4.66$, $P=0.01)$ peak pressure on the sole, and significant $(F$-ratio $=14.63$, $P<0.01)$ differences across all individuals in peak pressure of the pedal digits (supplementary material Table S2). Significant individual variation in the PTI ratio was found during descent, with Individual A having higher $(F$-ratio $=16.57, P<0.01)$ pressures on the sole and Individual $C$ having higher $(F$-ratio $=17.52, P<0.01)$ pressures on the pedal digits compared with all other individuals (supplementary material Table S3).

\section{DISCUSSION}

This report presents the first study of the pressures experienced by the hands (and feet) during quadrupedal locomotion in aye-ayes. Results show that although there is some individual variation, there are clear general trends with regard to hand posture, speed and pressure that characterize aye-aye locomotion. These trends reveal a composite strategy to reduce pressure on long, gracile digits. This study not only confirms previous behavioral data on hand posture but also reveals previously undocumented mechanisms for adaptation to locomotion on larger substrates that are frequently used by aye-ayes in the wild. These are alternative strategies to the postural adaptations, such as knuckle-walking, or morphological changes, such as reduced length of digits, that are documented in other primates, and this study reveals more clearly the plasticity of primate behavior overall. The various behavioral adaptations to digit load reduction shown by aye-ayes in this study may not only be informative for understanding the adaptive mechanisms used by other mammals with similar, convergent digit morphology but for animals in which reduced load on the forelimbs may be generally advantageous.

Aye-ayes have highly gracile, elongated digits that are at risk of incurring high loads during locomotion, especially during head-first descent. We hypothesized that pressures would increase on the hand during head-first descent (and decrease during ascent) but that the manual digital pressures would be negligible relative to those of the palm or pedal digits, or avoided altogether by curling their fingers off the substrate. Our results support these hypotheses and also reveal novel strategies that moderate pressure on the long digits of the ayeaye. Our data show that aye-ayes ameliorate pressures experienced by their digits in several ways. First, their speed of descent was significantly slower than their horizontal and ascending locomotion. Lammers et al. (Lammers et al., 2006) found that the gray shorttailed opossum moved more slowly during both ascent and descent, but the aye-aye used a slower speed during head-first descent only. The aye-ayes ascended substrates at the fastest speed, though there may be non-biomechanical reasons for this, including the common strategy among primates to be up high or climb as a natural escape response (Scheumann et al., 2007). Reducing speed can reduce load experienced by the palm and digits (Demes et al., 1994), but does not always do so because the pressure and force patterns can be influenced by hand posture (Patel, 2008).

Thus, as a second mechanism, aye-ayes in this study used handpostures that reduce or simply avoid bending loads experienced by the digits. The aye-ayes typically curled their fingers up off the substrate, as Oxnard et al. (Oxnard et al., 1990) described, such that the most specialized digits, including the third and fourth, evaded any risk of bending stress. The pollex, which is the shortest and most robust, was the only manual digit that was regularly loaded during locomotion. Individual variability in hand postures (and pressures) was noted, which is consistent with the high variability already documented by Krakauer et al. (Krakauer et al., 2002) on arboreal substrates. Use of the manual digits was more common during descent and ascent than during horizontal locomotion, suggesting that the fingers may provide additional stability on more uncertain substrates.

Third, aye-ayes typically lifted their hands vertically off the substrate, as opposed to rolling off the digits at the end of step like the toe-off locomotion used by the foot. This behavior during quadrupedal locomotion means that manual digits are not being used to push off the substrate at the end of a step and thus bending loads are greatly reduced. This is also a novel finding and suggests further avenues for exploration of patterns of toe-off in primates and other mammals in terms of load reduction. Furthermore, the proximal portion of the palm experiences the greatest pressure, which may reduce the load arm but increase compressive loads at the antebrachiocarpal, midcarpal and/or carpometacarpal joints. These results are consistent with the observation that, compared with other lemurs, aye-ayes have a robust scaphoid with an expansive radial facet and a mediolaterally broad hamate, suggesting that the 
antebrachiocarpal and midcarpal joints may be better able to resist compressive loads (T.L.K., unpublished data). However, formal analyses of adaptation of the bony morphology of the carpus and metacarpus to such unique digit morphology and hand postures are needed.

This study shows that even when the manual digits of aye-ayes are touching the substrate, they experience relatively little pressure and contact the substrate for less time than the pedal digits. When the fingers were used during locomotion, the peak pressure, PTI and contact time were substantially lower than those experienced by the palm or pedal digits across all slopes (Fig. 3). Furthermore, peak pressures experienced by the fingers did not significantly increase during head-first descent compared with ascent. Even as speed increased, the PTI ratio experienced by the manual digits (and palm) decreased (Table 3B). These results support our hypothesis that loads experienced by the manual digits are relatively negligible.

Finally, aye-ayes may be reducing loads on the manual digits via an additional locomotor or biomechanical adaptation. Krakauer et al. (Krakauer et al., 2002) posited that aye-ayes may reduce the load borne by the fingers by shifting their weight more posteriorly, to their hindlimbs, than when traversing horizontal substrates. Analysis of the relative difference in overall pressures experienced by the hand versus the foot revealed some interesting patterns. During horizontal locomotion, the aye-aye foot experiences more of the total PTI (mean 56\%) than the hand (44\%). Furthermore, both the peak pressure and the PTI ratio of the foot, but not the hand, increased with speed. This pattern is consistent with previous research demonstrating that primates, unlike most quadrupedal mammals, experience higher peak vertical forces on the hindlimbs than they do on the forelimbs (Kimura et al., 1979; Reynolds, 1985; Demes et al., 1994; Schmitt and Lemelin, 2002). Although this previous research analyzed peak vertical force (peak pressure times area of contact), a comparable ratio of the peak pressure during horizontal locomotion demonstrates that aye-ayes are most similar to Lemur fulvus and some Old World monkeys in a ratio of relative load experienced by the hand (forelimb) over the foot (hindlimb) [forelimb/hindlimb $=0.88$ in aye-ayes compared with 0.67 in $L$. fulvus, 0.78 in Chlorocebus aethiops, and 0.90 in Erythrocebus patas and Miopithecus talapoin (Demes et al., 1994; Reynolds, 1985)].

When aye-ayes walked on an inclined substrate, there was a substantial shift in the peak pressure and the PTI ratio from the hands to the feet. The feet experienced $75 \%$ of the total PTI ratio and the hands only $25 \%$ during ascent. This posterior shift in load during inclined relative to horizontal locomotion is consistent with previous research on other non-primate, quadrupedal mammals (Dutto et al., 2004; Lammers et al., 2006; Lammers, 2007). However, we did not find an equivalent inverse shift in pressure from the feet to the hands during head-first descent. Instead, the feet and hands still retain a relatively equal distribution of the total load $(54 \%$ and $46 \%$ of the total PTI for the hands and feet, respectively). Although the PTI ratio did shift to the hands during descent relative to horizontal locomotion ( $10 \%$ change), this shift was less than half that of the shift towards the feet during ascent (21\%). It was also not as much as the $15 \%$ increase in forelimb load during descent that was reported for the gray short-tailed opossum (Lammers et al., 2006). This variation suggests that, relative to horizontal locomotion, aye-ayes probably shift their weight posteriorly during head-first descent, thereby reducing loads on the palm and fingers, as Krakauer et al. (Krakauer, 2002) hypothesized. The mechanism by which aye-ayes accomplish this posterior weight shift deserves further testing and we must keep in mind complicating factors, such as the role of propulsive versus braking forces, and the fact that primates naturally carry higher loads on their hindlimbs. An understanding of the substrate reaction forces experienced by the limbs and whole-body center of mass in ayeayes as well as other strepsirrhines is needed to understand fully how this unique primate has reconciled its seemingly paradoxical morphology and locomotion. However, this first analysis of ayeaye pressure distribution between the limbs strongly suggests, especially in comparison to the few other studies on non-primate mammals, that aye-ayes are adopting a potentially novel posteriorweight-shifting mechanism that reduces bending stress on their digits during head-first descent. A similar mechanism may be used by spider monkeys, which also have elongated fingers necessary for suspension but do not use a curled-digit hand posture like that of the great apes. Analyses of spider monkey substrate reaction forces has shown that the forelimb experienced significantly less load relative to the hindlimb than in other primates, suggesting that they may also shift their weight posteriorly over the hindlimb (Kimura, 1985; Schmitt, 1994; Demes et al., 1994), although this hypothesis has yet to be empirically tested. Similar mechanisms may be used by other long-fingered mammals, such as the long-fingered triok, and further investigation of these species may reveal general patterns of behavioral adaptation that can be used to interpret similar functional morphology in the fossil record.

The aye-aye encompasses extremes of both morphological and locomotor constraints, and its solution to the biomechanical challenge of loading gracile digits adapted for complex manipulative tasks demonstrates the critical adaptive plasticity of primates to deal with the selective pressures of an arboreal environment. The unique adaptive strategies utilized by the aye-aye may be the result of a long evolutionary history. Remarkably, the giant fossil aye-aye ( $D$. robusta) has the same specialized digit morphology but is estimated to be three to five times larger in body size than extant aye-ayes (Simons, 1994). D. robusta may have adapted its locomotor behavior in a similar manner to that of extant aye-ayes, both by altering its hand posture and slowing down during head-first descent, so as not to impose high loads on their specialized fingers.

\section{ACKNOWLEDGEMENTS}

We are grateful to Sarah Zehr, Dave Brewer, Erin Nemecek and all of the staff at the Duke Lemur Center for without their help and patience, this research would not have been possible. We thank Rita Baumgartner, Anita Pai and especially Elizabeth Kramer who helped with data collection. We thank David Haring for generously sharing his aye-aye images. We are grateful to Andrew Biewener and three anonymous reviewers whose thoughtful comments greatly improved this manuscript. This research was supported by the Jeffress Memorial Trust to R.E.W. and by Duke Undergraduate Research Support.

\section{REFERENCES}

Ancrenaz, M., Lackman-Ancrenaz, I. and Mundy, N. (1994). Field observations of aye-ayes (Daubentonia madagascariensis) in Madagascar. Folia Primatol. 62, 22-36. Ashton, E. H., Flinn, R. M. and Oxnard, C. E. (1975). The taxonomic and functional significance of overall body proportions in primates. J. Zool. 175, 73-105.

Cartmill, M. (1972). Arboreal adaptations and the origin of the order Primates. In The Functional and Evolutionary Biology of Primates (ed. R. H. Tuttle), pp. 3-35. Chicago: Aldine-Atherton.

Cartmill, M. (1974). Daubentonia, Dactylopsila,woodpeckers and klinorhynchy. In Prosimian Biology (ed. R. D. Martin, G. A. Doyle and A. C.Walker), pp. 665-670. London: Duckworth.

Cartmill, M. (1992). New views on primate origins. Evol. Anthrop. 1, 105-111.

Curtis, D. A. and Feistner, A. T. C. (1994). Positional behavior in captive aye-ayes (Daubentonia madagascariensis). Folia Primatol. 62, 155-159.

D'Août, K., Vereecke, E., Schoonaert, K., DeClercq, D., Van Elsacker, L. and Aerts, P. (2004). Locomotion in bonobos (Pan paniscus): differences and similarities between bipedal and quadrupedal terrestrial walking and a comparison with other locomotor modes. J. Anat. 204, 353-361.

Demes, B., Larson, S. G., Stern, J. T., Jr, Jungers, W. L., Biknevicius, A. R. and Schmitt, D. (1994). The kinetics of primate quadrupedalism: "hindlimb drive" reconsidered. J. Hum. Evol. 26, 353-374.

Dutto, D. J., Hoyt, D. F., Cogger, E. A. and Wickler, S. J. (2004). Ground reaction forces in horses trotting up an incline and on the level over a range of speeds. J. Exp. Biol. 207, 3507-3514. 
Elftman, H. and Manter, J. (1935). Chimpanzee and human feet in bipedal walking Am. J. Phys. Anthropol. 20, 69-79.

Erickson, C. J. (1994). Tap-scanning and extractive foraging in aye-ayes, Daubentonia madagascariensis. Folia Primatol. 62, 125-135.

Flannery, T. F. (1995). Mammals of New Guinea. Chatswood: Australian Museum/Red Books.

Gebo, D. L. (1996). Climbing, brachiation and terrestrial quadrupedalism: historical precursors of hominid bipedalism. Am. J. Phys. Anthropol. 101, 55-92.

Hamrick, M. W. (2001). Primate origins: Evolutionary change in digital ray patterning and segmentation. J. Hum. Evol. 40, 339-351.

Hunt, K. D., Cant, J. G. H., Gebo, D. L., Rose, M. D., Walker, S. E. and Youlatos, D. (1996). Standardized descriptions of primate locomotor and postural modes. Primates 37, 363-387.

Inouye, S. E. (1994). Ontogeny of knuckle-walking hand postures in African apes. J. Hum. Evol. 26, 459-485.

Jouffroy, F. K. (1975). Osteology and myology of the lemuriform postcrania skeleton. In Lemur Biology (ed. I. Tattersall and R. W. Sussman), pp. 149-192. New York: Plenum Press.

Jouffroy, F. K. and Lessertisseur, J. (1979). Relationship between limb morphology and locomotor adaptations among prosimians: an osteometric study. In Environment, Behavior, and Morphology: Dynamic Interactions in Primates (ed. M. A. Morbeck, H. Preuschoft and N. Gomberg), pp. 143-181. New York: Gustav Fischer.

Jouffroy, F. K., Godinot, M. and Nakano, Y. (1991). Biometrical characteristics of primate hands. Hum. Evol. 6, 269-306.

Kimura, T. (1985). Bipedal and quadrupedal walking of primates: comparative dynamics. In Primate Morphophysiology, Locomotor Analyses and Human Bipedalism (ed. S. Kondo, H. Ishida, T. Kimura, M. Okada, M. Yamazaki and J. Prost), pp. 47-58. Toyko: University of Toyko Press.

Kimura, T., Okada, M. and Ishida, H. (1979). Kinesiological characteristics of primate walking: its significance in human walking. In Environment, Behavior and Morphology: Dynamic Interactions in Primates (ed. M. E. Morbeck, H. Preschoft and N. Gomberg), pp. 297-311. New York: G. Fischer.

Krakauer, E., Lemelin, P. and Schmitt, D. (2002). Hand and body position during locomotor behavior in the aye-aye (Daubentonia madagascariensis). Am. J. Primatol. 57, 105-118.

Lammers, A. R. (2007). Locomotor kinetics on sloped arboreal and terrestrial substrates in a small quadrupedal mammal. Zoology 110, 93-103.

Lammers, A. R., Earls, K. D. and Biknevicius, A. R. (2006). Locomotor kinetics and kinematics on inclines and declines in the gray short-tailed opossum Monodelphis domestica. J. Exp. Biol. 209, 4154-4166.

Lee, D. V., McGuigan, M. P., Yoo, E. H. and Biewener, A. A. (2008). Compliance, actuation and work characteristics of the goat foreleg and hindleg during level, uphil and downhill running. J. App. Physiol. 104, 130-141.

Lemelin, P. (1996). The Evolution of Manual Prehensility in Primates. A Comparative Study of Prosimian Primates and Didelphid Marsupials, Dissertation. State University of New York at Stony Brook, Stony Brook, NY, 534 pp. Available from: University Microfilms, Ann Arbor, Ml: AAG9637185.

Lemelin, P. (1999). Morphological correlates of substrate use in didelphid marsupials: implications for primate origins. J. Zool. 247, 165-175

Lemelin, P. and Grafton, B. (1998). Grasping performance in Saguinus midas and the evolution of hand prehensility in primates. In Primate Locomotion (ed. E. Strasser and J. G. Fleagle), pp. 131-144. New York: Plenum Press.

Lemelin, P. and Jungers, W. L. (1997). Body size and scaling of the extremities of prosimian primates. Am. J. Phys. Anthropol., Suppl. 24, 153.

Lemelin, P. and Schmitt, D. (1998). The relation between hand morphology and quadrupedalism in primates. Am. J. Phys. Anthropol. 105, 185-197.

Lemelin, P. and Schmitt, D. (2007). Origins of grasping and locomotor adaptation in primates: Comparative and experimental approaches using an opossum model. In Primate Origins: Adaptation and Evolution (ed. M. J. Ravosa and M. Dagosto), pp 329-380. New York: Springer.

Lessertisseur, J. and Jouffroy, F. K. (1973). Tendances locomotrices des primates traduites par les proportions du pied: L'adaptation à la bipédie. Folia Primatol. 20, 125-160.

Milliken, G. W., Ward, J. P. and Erickson, C. J. (1991). Independent digit control in foraging by the aye-aye (Daubentonia madagascariensis). Folia Primatol. 56, 219-224.

Napier, J. H. (1963). Brachiation and brachiators. Symp. Zool. Soc. Lond. 10, 183-194.

Napier, J. H. and Napier, P. H. (1967). A Handbook of Living Primates. London: Academic Press.

Oxnard, C. E. (1981). The uniqueness of Daubentonia. Am. J. Phys. Anthropol. 54, 1 21.

Oxnard, C. E., Crompton, R. H. and Lieberman, S. S. (1990). Animal Lifestyles and Anatomies: The Case of the Prosimian Primates. Seattle: University of Washington Press.

Owen, R. (1866). On the aye-aye (Chiromys Cuvier). Trans. Zool. Soc. Lond. 5, 33-101.
Patel, B. A. (2008). Biomechanics and Functional Morphology of Digitigrade Hand Postures in Cercopithecoids Primates [Dissertation]. Stony Brook (NY): State University of New York at Stony Brook, 229 pp. Available from: University Microfilms, Ann Arbour, MI; AAT 3338242.

Patel, B. A. and Wunderlich, R. E. (2010). Dynamic pressure patterns in the hands of olive baboons (Papio anubis) during terrestrial locomotion: implications for cercopithecoid primate hand morphology. Anat. Rec. 293, 710-718.

Preuschoft, H. and Günther, M. M. (1994). Biomechanics and body shape in primates compared with horses. Z. Morphol. Anthropol. 80, 149-165.

Preuschoft, H., Godinot, M., Beard, C., Nieschalk, U. and Jouffroy, F. K. (1993) Biomechanical considerations to explain important morphological characters of primate hands. In Hands of Primates (ed. H. Preuschoft and D. J. Chivers), pp. 245 256. Berlin: Springer-Verlag.

Prost, J. H. and Sussman, R. W. (1969). Monkey locomotion on inclined surfaces. Am. J. Phys. Anthropol. 31, 53-58.

Quinn, G. P. and Keough, M. J. (2002). Experimental Design and Data Analysis for Biologists. Cambridge: Cambridge University Press.

Raichlen, D. A. (2004). Convergence of forelimb and hindlimb natural pendular periods in baboons (Papio cynocephalus) and its implication for the evolution of primate quadrupedalism. J. Hum. Evol. 46, 719-738.

Raichlen, D. A. (2005). Effects of limb mass distribution on the ontogeny of quadrupedalism in infant baboons (Papio cynocephalus) and implications for the evolution of primate quadrupedalism. J. Hum. Evol. 49, 415-431.

Reynolds, T. R. (1985). Stresses on the limbs of quadrupedal primates. Am. J. Phys. Anthropol. 67, 351-362.

Richmond, B. G. (1998). Ontogeny and Biomechanics of Phalangeal Form in Primates [Dissertation]. Stony Brook (NY): State University of New York at Stony Brook, 240 pp. Available from: University Microfilms, Ann Arbour, Ml; AAT 9917470.

Schaal, S. and Ziegler, W. (1992). Messel: An Insight into the History of Life and of the Earth. Oxford: Clarendon Press.

Scheumann, M., Rabesandratana, A. and Zimmerman, E. (2007). Predation, communication and cognition in lemurs. In Primate Anti-predator Strategies (ed. S. Gursky and K. A. I. Nekaris), pp. 100-126. New York: Springer.

Schmitt, D. (1994). Forelimb mechanics as a function of substrate type during quadrupedalism in two anthropoid primates. J. Hum. Evol. 26, 441-457.

Schmitt, D. and Lemelin, P. (2002). Origins of primate locomotion: gait mechanics of the woolly opossum. Am. J. Phys. Anthropol. 118, 231-238.

Simons, E. L. (1994). The giant aye-aye Daubentonia robusta. Folia Primatol. 62, 1421.

Soligo, C. (2005). Anatomy of the hand and arm in Daubentonia madagascariensis: a functional and phylogenetic outlook. Folia Primatol. 76, 262-300.

Sterling, E. J. and McCreless, E. E. (2006). Adaptations in the aye-aye: a review. In Lemurs: Ecology and Adaptation (ed. L. Gould and M. L. Sauther), pp. 159-184 New York: Springer.

Strasser, E. (1992). Hindlimb proportions, allometry, and biomechanics in Old World monkeys (Primates, Cercopithecidae). Am. J. Phys. Anthropol. 87, 187-213.

Strasser, E. (1994). Relative development of the hallux and pedal digit formulae. $J$. Hum. Evol. 26, 413-440.

Susman, R. L. (1974). Facultative terrestrial hand postures in an orangutan and pongid evolution. Am. J. Phys. Anthropol. 40, 27-38.

Swartz, S. M. and Biewener, A. A. (1992). Shape and scaling. In Biomechanics: Structures and Systems (ed. A. A. Biewener), pp. 21-43. Oxford: Oxford University Press.

Tuttle, R. H. (1967). Knuckle-walking and the evolution of hominoid hands. Am. J. Phys. Anthropol. 26, 171-206.

Tuttle, R. H. (1969). Knuckle-walking and the problem of human origins. Science 166 953-961.

Vereecke, E., D’Août, K., De Clercq, D., Van Elsacker, L. and Aerts, P. (2003) Dynamic plantar pressure distribution during terrestrial locomotion of bonobos ( $P a n$ paniscus). Am. J. Phys. Anthropol. 120, 373-383.

Vereecke, E., D'Août, K., Van Elsacker, L., De Clercq, D. and Aerts, P. (2005) Functional analysis of the gibbon foot during terrestrial bipedal walking: plantar pressure distributions and three-dimensional ground reaction forces. Am. J. Phys. Anthropol. 128, 659-669.

Vilensky, J. A., Moore, A. M. and Libii, J. N. (1994). Squirrel monkey locomotion on an inclined treadmill: implications for the evolution of gaits. J. Hum. Evol. 26, 375386

Wunderlich, R. E. (1999). Pedal Form and Plantar Pressure Distribution in Anthropoid Primates [Dissertation]. Stony Brook (NY): State University of New York at Stony Brook, 619 pp. Available from University Microfilms, Ann Arbour, Ml; AAT 9943939.

Wunderlich, R. E. (2003). Dynamics of foot use during bipedal and quadrupedal walking in Pan troglodytes. Am. J. Phys. Anthropol. S36, 228.

Wunderlich, R. E. and Jungers, W. L. (2009). Digital pressures during knucklewalking in chimpanzees (Pan troglodytes). Am. J. Phys. Anthropol. 139, 394-403. 